\title{
Viviendo con el mar: inestabilidad litoral y territorios en movimiento en La Barra, Pacífico colombiano
}

\author{
Living with the Sea: Littoral Instability and Territories \\ in Motion in La Barra, Colombian Pacific Coast
}

María Isabel Galindo Orrego*

Universidad Icesi, Colombia

\section{RESUMEN}

En las playas de La Barra, a orillas del océano Pacífico colombiano, la vida acontece amarrada al movimiento del mar. La inquietud acerca de cómo se perfilan formas de habitar en medio del cambio permanente suscitado por el empuje del agua y cómo tal inestabilidad es asimilada por quienes la experimentan son las preguntas que inspiran esta indagación. El artículo rastrea etnográficamente la formación de La Barra al compás de las mutaciones del entorno y explora las explicaciones que los saberes locales otorgan a dicha alteración. Desde una mirada antropológica que dialoga con la historia ambiental, este trabajo piensa la agencia humana en relación con las agitaciones de la naturaleza mediante una trama telúrica que liga la humanidad a las transformaciones de la tierra.

Palabras clave: inestabilidad litoral, La Barra, océano Pacífico colombiano, trama telúrica.
DOI: https://doi.org/10.22380/2539472X.569

\begin{abstract}
$\overline{\text { ABSTRACT }}$
In the beaches of La Barra, on the shores of the Colombian Pacific Ocean, the life is tied to the movement of the sea. The questions that inspire this inquiry are how ways of living are outlined amidst constant change aroused by the thrust of the water and how this instability is assimilated by those who experience it. This article tracks ethnographically the formation of La Barra to the rhythm of the environment's transformations, and explores the local explanations to such alterations. From an anthropological point of view in dialogue with environmental history, this work aims to think human agency in relation to nature's agitations through a telluric weave that links humanity to the transformations of the earth.
\end{abstract}

Keywords: Coastal instability, La Barra, CoIombian Pacific Ocean, telluric weave.

Docente e investigadora de la Universidad Icesi (Cali). Este artículo hace parte de la investigación realizada para la obtención del título de magíster en Estudios Sociales y Políticos de la Universidad Icesi (2015-2017). Su última publicación es la reseña "Incertidumbre, provisionalidad e independencia: ¿sujeción o libertad?", Revista CS 17 (2015): 185-187. mariaisabelgalindo47@gmail.com. 


\title{
Introducción ${ }^{1}$
}

\author{
Por el perdón del mar \\ nacen todas las playas \\ sin razón y sin orden, \\ una cada mil años, \\ una cada cien mares [...]. \\ (In Limine, Fabio Morábito)
}

Hay en este mar no sé qué dulce misterio; su oleaje suave, pero terrible, parece hablar de un espíritu oculto [...] este divino y misterioso Pacífico [...] parece el corazón del mundo, que late con sus mareas.

(Moby Dick, Herman Melville)

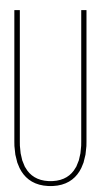

na perpetua alteración gobernada por el océano inexorable conversa con una manera particular de estar en el mundo. En las playas de La Barra, como en otras poblaciones costeras, la forma de la vida está ligada al movimiento del mar. Para las 130 familias barreñas el mar es el correlato de una historia en la que el espacio y el tiempo se trazan al vaivén de una implacable marea, al ritmo de impetuosas pujas ${ }^{2}$ y de quiebras sosegadas. En enero del 2008 conocí esta población pesquera asentada pocos kilómetros al sur de la desembocadura del río San Juan, límite geográfico entre el departamento del Valle del Cauca y el Chocó en el Pacífico colombiano (véase figura 1). El recuerdo de mis visitas recurrentes dibuja un lugar distinto al que hoy existe. El pueblo de mi memoria, y de la de quienes maduraron su juventud siendo testigos de la transformación, ya no está. Ahora el océano ocupa el espacio antes habitado que, al decir de los mayores, siempre le perteneció.

En abril y septiembre del 2014 algunos diarios anunciaron que un "fuerte oleaje causa daños en unas 72 viviendas de La Barra, Buenaventura”, y aseguraban pre el camino, por su tiempo y sus palabras. También agradezco a Enrique Jaramillo, Diego Cagüeñas, Nancy Motta y a los editores de este número por sus valiosos comentarios.

2 A lo largo del texto aparecerán en cursiva expresiones propias del lugar, además de algunas categorías que propone este trabajo que serán especificadas. Las pujas son mareas de mucha fuerza, que coinciden con la luna llena y la luna nueva, en las que el agua sube y baja más. Las quiebras se presentan en cuarto menguante y cuarto creciente, y la oscilación de la marea es menor. Más adelante me extenderé al respecto. 
que el "Océano Pacífico amenaza con desaparecer La Barra”3. Las noticias, redactadas desde el lado oriental de la cordillera que separa el valle del mar, reseñaban además las impresiones que el evento había causado en la población afectada: "esta puja fue horrible. El agua entró tumbando todo", decía Alexis Mosquera, presidente en ese entonces del Consejo Comunitario de la Comunidad Negra de La Barra $^{4}$. Otra versión local, referida también en las noticias, declaraba que "esta puja fue grandísima, nos volvió a asustar, aunque ya son tantos los enviones que nos ha hecho el mar, que nos estamos acostumbrando", comentó Eliécer Posso, profesor de la escuela y representante legal del consejo comunitario.

Dos años antes de que los enviones del mar golpearan La Barra, escribí en mi diario de campo el recuerdo de conversaciones con un par de amigos barreños que intuían algo de lo que sucedió, a pesar de que las preguntas que me condujeron a este lugar no contemplaban su impacto:

La titulación de tierras en La Barra está marcada por la dificultad de apropiarse de espacios que de repente pueden dejar de existir debido a la amenaza que el mar ejerce. Quienes viven ahí no piensan moverse de su playa. Cuenta "Cerebro", pescador que también trabaja con el turismo, que "el mar se lleva vuelta ${ }^{5}$ la playa que trajo"; antes había mar donde ahora hay playa y ahora hay playa donde habrá mar. (Marzo del 2012)

Varios años después, este registro mantiene su vigencia. Plácido Salazar Pretel, pescador veterano, me contó que el Gobierno no envió ninguna ayuda luego de que a finales del 2013 el mar arrasara con casi todo lo que tenía. Reclama, como muchos otros, ser desplazado de un mar que está recuperando terreno.

En este escenario de enviones y arremetidas del mar, indago por las transformaciones del entorno y sus vínculos con las actividades humanas, que también lo modifican. Mi propuesta sigue la pista de quienes han pensado la región del Pacífico colombiano desde una perspectiva que concibe la construcción social del espacio considerando a su vez una realidad no humana con la que se ha

3 Para ampliar, véase http://www.elpais.com.co/valle/fuerte-oleaje-causa-danos-en-unas-72-vi viendas-de-la-barra-buenaventura.htm; http://www.elpais.com.co/valle/daminificados-dela-barra-en-buenaventura-reclaman-ser-reubicados-tras-emergencia.htm; http://www.pulzo. com/cali/oceano-pacifico-amenaza-con-desaparecer-la-barra-corregimiento-de-buenaventu $\mathrm{ra} / 208486$.

4 El consejo comunitario constituye la autoridad política local de los territorios colectivos de comunidades negras. Está conformado por una asamblea general y una junta directiva, además de algunos comités de trabajo. En el 2002 la comunidad se organizó bajo esta figura, cuyo logro más importante ha sido el título colectivo de poco más de 3.000 hectáreas otorgado en julio del 2015.

5 En La Barra, vuelta es una expresión que indica "de nuevo", "otra vez", y se inscribe en una suerte de temporalidad cíclica. 
coproducido dicha configuración cultural. Las maneras en que los pueblos del litoral se relacionan con el ambiente, lo apropian, recrean y modifican son los temas que atraviesan tales reflexiones ${ }^{6}$. Transitando dicho camino, este artículo pretende contribuir a la discusión sobre una historia ambiental del Pacífico colombiano que, a través de una mirada antropológica urdida en el ejercicio etnográfico, centre su atención en la forma en que los barreños, en particular, y los pueblos costeros, en general, entienden y experimentan la transformación de su mundo litoral por la acción de la fuerza del agua. Así, a la luz de la exigencia que proclama John McNeill (2005) con el fin de superar el sesgo "terrenal” de la historia ambiental, este trabajo reivindica la presencia y la fuerza del mar como agente acuático de la historia. En ese sentido, espera aportar a la construcción de una antropología del agua que, en este caso, permitiría comprender la vida de comunidades cuya historia se ha tejido en estrecha relación con el mar.

Por medio de una aproximación etnográfica que dialoga con la historia ambiental, esta investigación se pregunta cómo se perfilan formas de vida en medio del cambio permanente y cómo son articuladas dichas inestabilidades en configuraciones territoriales que devienen tanto discursivas como materiales. El empuje del agua y las erosiones de la tierra dibujan territorios a la vez imaginados y construidos por el trazo de las manos humanas. Así, la territorialidad se entiende como una forma de habitar en la que el sentido de lugar ${ }^{7}$ se amarra inextricablemente al ímpetu permisivo e intransigente del entorno biofísico, y contribuye a pensar cómo la agencia humana se halla en continua interacción con las agitaciones de una naturaleza en incesante transformación mediante una trama que es al mismo tiempo tejido e historia. En ese sentido, este escrito teje una historia del cambio en la que el mundo está en movimiento tanto como los seres que lo habitan e ilustra una forma de vida que está, como la misma tierra, en permanente construcción ${ }^{8}$.

Estas han sido abordadas desde diferentes marcos conceptuales y en diversos contextos de investigación por los estudios sociales. Sobre geografía histórica, económica y cultural, véanse, entre otros, Herrera (2016), Leal (2000, 2008), Oslender (2004, 2008), Pedrosa (1996), West ([1957] 2000). Sobre patrones de asentamiento e historia del poblamiento, véanse AprileGniset (1993); Mosquera (1993, 2010); Vanín (1996). Acerca de estudios antropológicos sobre los lazos que urden las comunidades con el entorno, véanse Arocha (1999), Escobar (1999, 2014), Giraldo (2009), Losonczy (1993, [1997] 2006), Motta (2005), Restrepo (1996a, 1996b). Sobre historia económica y ambiental, véanse Leal y Restrepo (2003), Motta y Perafán (2010), Perafán (2013), Leal y Van Ausdal (2014).

7 Siguiendo a Oslender (2008), se entenderá el sentido de lugar como los aspectos subjetivos que nacen de la vida en un espacio en particular y que ligan, a través de la memoria y la experiencia, a los seres humanos con el entorno físico (91).

8 En la formación y destrucción de playas por efecto del agua se despliega una forma de habitar mediada por una reconstrucción continua del universo material que conlleva una 
La aproximación que sugiero rastrea la manera en que los habitantes de La Barra conversan con las mutaciones del entorno a través de la confección de una ligazón telúrica (que es histórica, maleable y contingente) que los vincula con este espacio costero. En La Barra, según dice la gente, los seres y elementos del litoral conviven con las rabietas del mar: es sabido que este es celoso con la arena y por eso la roba, la trae vuelta y forma de nuevo la playa. La selva circundante, además, devuelve lo que se lleva la marea. En este vaivén, que se parece mucho al movimiento mismo del mar, cuyo carácter es el de un agente vivo y voluntarioso, la tierra esculpida por el agua da forma a sociedades costeras como La Barra, que al mismo tiempo la nombran, apropian y modifican. La creación recíproca entre humanos y ambiente - la afectación de la naturaleza mediante las prácticas humanas y la alteración de estas al compás de las metamorfosis del entorno- es la fuerza que inspira esta intuición. Una trama telúrica $a^{9}$ - que es terrestre y acuática- teje la vida y el sentido de lugar: sobre las huellas de una latente destrucción, los barreños se niegan a alejarse de su mar. Porque el mar se lleva vuelta la playa que trajo y puede traer vuelta la playa que se llevó.

El trabajo de campo se desarrolló entre enero y julio del 2016. La información consignada en este artículo es producto de mi propia observación y experiencia en terreno, registradas en diario de campo, entrevistas en profundidad y conversaciones informales con habitantes del lugar que han vivido e interpretado la transformación de sus playas. El ejercicio de rastrear la historia local mediante narraciones orales me permitió recrear un relato en movimiento que resulta fiel a un devenir en transformación y alimenta la posibilidad de captar la perspectiva de la gente que revela el conocimiento local. Los nombres que aparecen en este artículo no son seudónimos: tienen la impronta de quienes me contaron su vida con la licencia de relatarla más allá de sus playas. Encarnan un sentido biográfico propio de una historia que nace de narraciones de vidas particulares (y en la escritura he querido respetar dicha singularidad), que desde lo peculiar iluminan un acaecer compartido cuyo tiempo está hecho de las edades pasajeras de quienes le dan forma. Finalmente, atendiendo a la exploración historiográfica de otro tipo de fuentes — como las fuerzas geológicas, los vientos, las

resignificación cultural. Esta alteración continua es rescatada también por Ingold (2013), quien afirma que, "como la misma Tierra, la superficie de cada sólido no es sino una corteza, el más o menos efímero congelamiento de un movimiento generativo" (27).

9 Articularé la trama telúrica como el tejido viviente (Motta 2005) que los pueblos del litoral traban con su entorno. Se trata tanto de una fuerza (agitaciones telúricas y fenómenos climáticos que conmocionan el espacio y que rebasan la existencia humana), pero que pueden modificarse parcialmente por la acción de esta, como de un vínculo (la ligazón existencial y epistémica que teje la comunidad con un lugar particular). 
Figura 1. Ubicación geográfica de La Barra

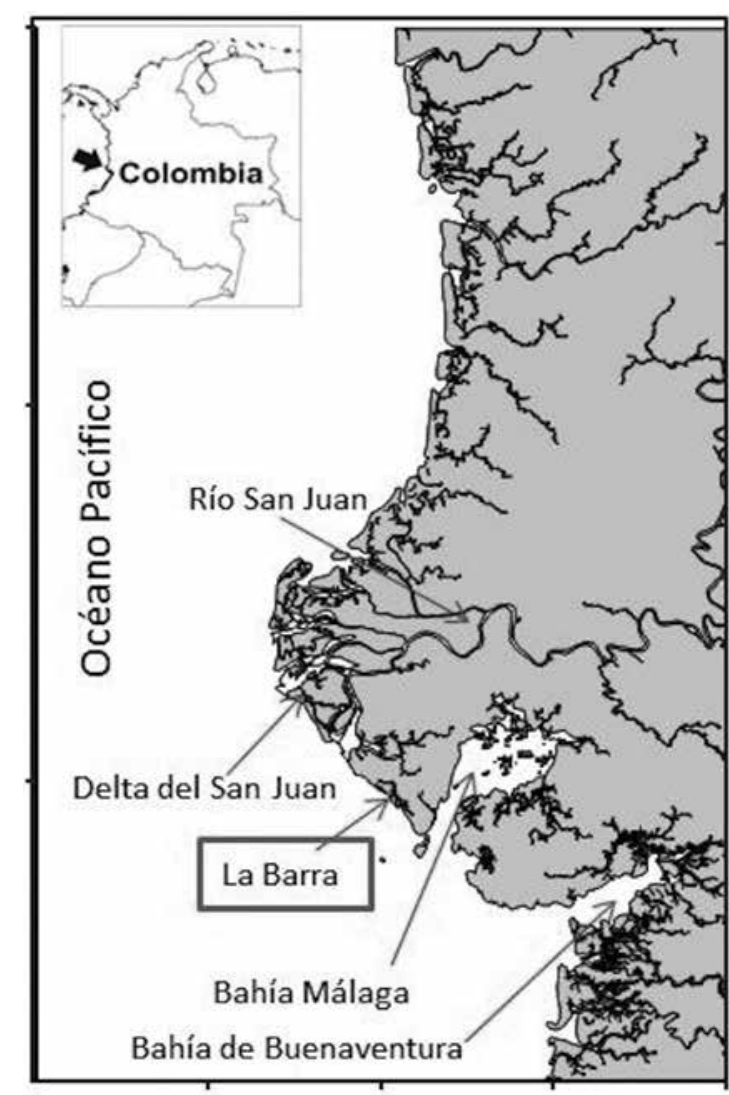

Fuente: elaboración propia sobre la base cartográfica del IGAC

(http://www.igac.gov.co/wps/portal/igac/raiz/iniciohome/MapasdeColombia/Descargas).

mareas-, defendida por la historia ambiental, indagué sobre fenómenos biofísicos que inciden en la transformación del entorno.

El artículo está organizado en tres secciones. La primera propone articulaciones entre la historia ambiental y la antropología, con la intención de mostrar cómo en La Barra la apropiación y significación del espacio interactúan con una historia "natural" moldeada por el agua. La segunda, dividida en tres apartados, reconstruye etnográficamente la descripción de un mundo en movimiento, los relatos sobre la movilidad humana y las transformaciones del entorno, y las explicaciones locales acerca de la destrucción y formación de playas, con el propósito 
de ilustrar una historia del cambio en la que se conjugan "vidas movidas" ${ }^{10}$ ” y paisajes cambiantes. La tercera presenta algunas consideraciones finales.

\section{Hacia una historia ambiental antropológica}

En el 2012, dos años antes de que las pujas destruyeran el caserío, llegué a las playas de La Barra queriendo rastrear la fuerza del monte, el mar, el manglar y los esteros a través de relatos de la gente sobre las visiones ${ }^{11}$ que median entre los seres humanos y la naturaleza misteriosa (Galindo 2012). Las arremetidas del mar esculpieron con el tiempo otro paisaje: mis intereses no se redujeron al embrujo de la selva sino que se fijaron en fuerzas telúricas que intervienen en la vida humana, pero que no se derivan exclusivamente de nuestra existencia ni dependen de nuestro lenguaje. Se abrió entonces la posibilidad de explorar los vínculos profundos que se construyen en la interacción de la historia humana y el largo devenir de la naturaleza.

La historia ambiental constituye la perspectiva teórica que me ha ayudado a pensar en la configuración del territorio de La Barra a través de la mutación constante del entorno. En consonancia con Stefania Gallini (2012), la investigación histórica debe contemplar "las complejas interacciones entre los sistemas social y biofísico, pensadas como flujos materiales y simbólicos” (391), y apuntar a una "rematerialización” del oficio historiográfico. Esta búsqueda avanza en ese sentido y espera aportar a la tarea de insertar la naturaleza en la historia y los contextos humanos, sin negar la existencia de procesos que encarnan una realidad biofísica independiente (Escobar 1999, 274). Lo interesante, en últimas, es pensar en "la interacción entre estructuras [...] naturales y sociales”, desde "la deriva continental" hasta los "flujos culturales" (Motta 2005, 29). En esa vía, la erosión marina, la sedimentación fluvial y los estremecimientos telúricos - entre otros fenómenos geofísicos - se mostrarán amarrados a la imaginación y las prácticas humanas. En el marco de la propuesta de Germán Palacio, de "vidas movidas", que cambian de lugar en relación con el espacio que otorgan el mar y el manglar.

11 Las visiones son entidades mediadoras entre la comunidad y el medio natural que la rodea. Se trata de figuras en las que se fusiona el carácter selvático y acuático del entorno con la humanidad de quien aparece como cualquiera. Su presencia ejerce un poder de atracción parecido al de la luna sobre las mareas y su naturaleza emula la cualidad embrujadora de la manigua que pierde a quien se adentra en sus dominios. 
la historia ambiental aborda el encuentro-colisión entre el acaecer humano y el de una naturaleza en transformación $(2002,194)$. Para este autor, el conflicto ambiental reviste la relación de los seres humanos y el entorno que los rodea y, en ese sentido, la historia ambiental se fija en dicha confluencia conflictiva, destructora y creadora. En esa vía se puede concebir el proceso de "erosión costera" que se presenta en las playas del Pacífico: creación y destrucción aparecen hermanadas en una dinámica a la que denominaré destrucción creadora.

El enfoque que propongo admite que no es posible entender la historia humana sin la historia natural y esta sin aquella, y exhorta a narrar las relaciones entre ambas (White 1995). Así, este trabajo permite examinar problemas que tienen que ver con "el diálogo ya muy antiguo entre los humanos y su planeta", y anima a pensar en "la tierra misma en tanto agente y presencia en la historia" (Worster 2008, 20-38). Diría, además, que el agua constituye el agente fundamental de transformación del entorno en La Barra y de la vida de quienes habitan dicho mundo. Siguiendo el planteamiento de John McNeill (2005), puede afirmarse que la historia ambiental ha privilegiado los ecosistemas terrestres. La existencia de espacios acuáticos - o "anfibios", como diría Orlando Fals Borda- exige análisis que contemplen formas de vida que dependen de sustratos distintos a la tierra misma. En La Barra, y en general en las sociedades que se han construido cerca de los cauces ribereños o en las orillas de los mares, la vida gira en torno al agua. La fuerza telúrica, uno de los conceptos que propone esta indagación, responde tanto al flujo de la energía terrestre como a la potencia hidráulica de las mareas, los ríos y las lluvias. En este sentido, procuraré combatir lo que según McNeill (2005) ha constituido un "sesgo terrenal" en la historia ambiental para dar forma a una historia telúrica tan terrestre como acuática.

No obstante, una aproximación que conciba los hilos que se tejen en la conversación del devenir humano y la transformación de la naturaleza demanda la comprensión de las relaciones que una sociedad dibuja con el entorno, considerando el conocimiento local que se construye respecto de este. La antropología constituye, en esa vía, la mirada desde la cual acercarse a la urdimbre que articula la vida social con un ambiente determinado y la etnografía abona el camino para hacerlo. He querido pensar la trama telúrica como el tejido que es el soporte de la vida. Se trata de una fuerza (temblores de tierra, arremetidas del mar, fenómenos climáticos) y de un vínculo (la ligazón que amarra a la comunidad con un espacio particular) en cuyo encuentro se despliega la territorialidad ${ }^{12}$. La

\footnotetext{
12 Vale la pena resaltar aquí que muchos barreños, hombres y mujeres, son carpinteros que tejen sus casas y que lo hacen tantas veces como el mar lo exige. Se trata de un "tejido viviente" que no es solo metafórico.
} 
epistemología local ${ }^{13}$ propuesta por Jaime Arocha (1999), o lo que Eduardo Restrepo (1996a) definió como gramática del entorno ${ }^{14} \mathrm{y}$ a lo que Ulrich Oslender (2008) denomina epistemologías acuáticas ${ }^{15}$ articulan el sentido del vínculo. Además de describir la trabazón existencial y epistémica que los pueblos del Pacífico colombiano construyen con su entorno, ya intuida por estos autores, en el concepto que sugiero subyace la dinámica misma de la tierra y del agua en relación con la cual se trazan singulares formas de habitar.

La ecología de la vida, defendida por Ingold (2000), exalta la inmanencia de los flujos de energía, los intercambios de materia y las manifestaciones de la mente como una "sinergia" de los organismos y sus entornos que se despliega en el "potencial generativo" que es la vida. Dicho potencial corresponde a una "totalidad indivisible" a la que propongo llamar trama telúrica para concebirla como un amarre apretado y profundo de los elementos humanos y no humanos de que está hecha, más que como una absoluta fusión de estos. Ingold inspira además otras posibilidades al concebir al ser humano como parte de un horizonte de relaciones en el que cada existencia acontece en una especie de "malla" formada por múltiples hilos entrelazados a la que ha denominado meshwork (2011, 63). Este antropólogo también piensa la historia como algo compuesto por el llegar-a-ser (porque no está hecho sino que está siendo continuamente) humano y no humano que dibuja un "tapiz” en incesante evolución. En ese sentido, adhiero a su forma de entender la antropología como "el acercamiento a los devenires humanos a medida que se desarrollan en el tejido del mundo" (Ingold 2011, 9, traducción propia). En consonancia con lo que aquí se expone, tal mundo no corresponde a una entidad inanimada que solo sirve de escenario para la vida humana; por el contrario, se trata de un universo en constante nacimiento cuyos residentes humanos afectan y son afectados por los fenómenos no humanos que esculpen y erosionan la superficie que ocupan (74). Con base en esta perspectiva, mostraré que en La Barra se mueven fuerzas hidráulicas, terrestres y atmosféricas que cimientan y socavan un espacio que a la vez es urdido por quienes lo habitan. Esta y emoción, de hábitos inconscientes y patrones de conducta, que responden ante la incertidumbre del medio a través de la "innovación cultural" (114-116).

14 Esta expresión, acuñada por Restrepo $(1996,69-70)$, atiende a la específica forma en que los grupos negros del Pacífico sur colombiano estructuran su propia lectura del medio que los rodea. Corresponde tanto a la apropiación física del entorno como a la forma en que es significado culturalmente (taxonomías, categorías y modelos cognitivos locales).

Formas locales de conocer el mundo asociadas con el espacio acuático, entendido como el escenario en que tienen lugar las interacciones y vínculos cotidianos entre las personas y el lugar caracterizado por redes de ríos, esteros y manglares (Oslender 2008, 133-135). 
historia ambiental antropológica quiere pensar cómo la vida humana en La Barra está siempre acaeciendo en relación con las mutaciones de un entorno agitado por el agua. La temporalidad de dicha configuración exige, además, una mirada histórica que permita entender la singularidad del devenir humano entretejido con una historia "natural" conmocionada por el mar.

\section{Historias del cambio: vidas movidas y paisajes cambiantes}

La línea de costa de $1.300 \mathrm{~km}$ sobre el Pacífico colombiano es un espacio de encuentro entre distintas fuerzas telúricas y humanas: la fiebre del oro, los deseos de fuga de grupos negros esclavizados, el mar, la tierra firme, los ríos y los vientos han chocado y se han mezclado en esta frontera inestable. Desde el tercer decenio del siglo XVII, las poblaciones afrodescendientes empezaron a predominar en las zonas de placeres auríferos y parte de las migraciones humanas en la región siguió el cauce de la explotación de oro hasta 1851, momento en que, con la abolición de la esclavitud, los otrora esclavizados se dispersaron desde la cabecera de los ríos hacia el litoral, poblando las tierras bajas del Pacífico colombiano (West [1957] 2000). Alfredo Vanín (1996) ha pensado este desplazamiento como una "línea de fuga" que es un viaje de las selvas al mar: "de la selva occidental africana hacia el océano abierto, de las minas de la zona alta de los ríos hacia las costas" (42). Los asentamientos dispersos, que caracterizaron el patrón de poblamiento de los grupos negros del Pacífico colombiano antes de la conformación de caseríos, se transformaron en aldeas organizadas en torno a relaciones parentales. Este rasgo se observa en todo el litoral y describe la manera en que los ritmos productivos, el crecimiento de las familias y la relación con el medio ambiente definieron la morfología de pueblos lineales fluviales y costeros (Aprile-Gniset 1993; Mosquera 2010).

En el litoral, la interacción del oleaje, los vientos, las mareas, las corrientes, la geomorfología del continente y las actividades humanas configuran dinámicas regidas por el constante movimiento y dibujan una historia hecha de intercambios, movilidad y transformaciones (Herrera 2016). La potente descarga de caudalosos ríos - además de la extrema pluviosidad, la minería, la tala y el desvío de algunos cauces que también estimulan procesos erosivos y de sedimentación-, la intensidad sísmica de la zona — asociada a la colisión de las placas de Nazca (corteza oceánica) y Suramericana (corteza continental)—y las marcadas 
oscilaciones de la marea dan forma a un escenario en perpetuo cambio. La formación de playas y la erosión costera (proceso de desgaste producto del choque continuo del mar contra la arena y las rocas de los acantilados) resultan de la combinación de procesos marinos, fluviales y tectónicos que confluyen en esta zona de contacto (Robertson 2003, 116).

Del fenómeno de erosión costera han sido testigo otros tiempos. Ya en 1957 Robert West intuía que la mutación del espacio físico constituye un rasgo fundamental de esta región:

Por toda la costa hay viejos de sesenta o setenta años que cuentan que en su juventud las crestas de playa eran mucho más anchas que ahora y que muchas de ellas estaban cubiertas de cocotales [...] Buena parte de este retroceso se debe a la acción de la marea y de las corrientes. Pero probablemente la mayoría de los cambios relatados por los habitantes han sido repentinos, y en algunos casos catastróficos. (West [1957] 2000, 102)

West, uno de los primeros investigadores en mirar hacia las tierras bajas del Pacífico colombiano, prestó especial atención a la influencia de las mareas en la formación de las playas y en cómo, además de robar espacio a la costa, el mar forma nuevas barreras terrestres. Tal como lo conciben en La Barra, el mar se lleva la arena pero también la devuelve. No solo la destrucción de playas es habitual: el crecimiento de estas es testigo del avance de la línea costera sobre el océano. El Pacífico es “un paisaje que nunca es igual”, cuyo carácter está teñido de incertidumbre y movimiento (Arocha 1999, 66). En él ocurren "fenómenos físicos que están modificando continuamente el paisaje de la llanura: sismicidad, volcanismo, vibraciones, tsunamis [...] marejadas, erosión y acrecentamiento de playas” (Pedrosa 1996, 33).

Antropólogos y geógrafos han confirmado el carácter inestable y cambiante del litoral. Las fuertes corrientes, las arremetidas del mar, los temblores y el desvío de los cauces fluviales constituyen elementos que configuran la "vida movida” e itinerante de los pueblos que ocupan la línea costera en estrecha intimidad con el agua, que cede o arrebata espacios para habitar. Son poblaciones “andariegas”, cuyos asentamientos aparecen y desaparecen mudándose de lugar (Giraldo 2009; Herrera 2016; Leal 2000). Ubicados sobre cordones litorales o "playas activas", como La Barra, estos pueblos dependen de “ciclos lentos de depósito de materiales alternados con otros de desgaste [...] la gente tiende a trasladar sus viviendas con arreglo a estos ciclos” (Gracia 2003, 256). Por otra parte, en el Pacífico sur colombiano los movimientos telúricos que se convierten en tsunamis han tenido efectos destructivos sobre algunas localidades, como la ciudad de Tumaco. La erosión costera en pueblos como "San Juan de la Costa, en Nariño, 
y Sivirú, en el sur del Chocó, ha obligado a la reubicación parcial o total de las poblaciones" (Robertson 2003, 110). La inestabilidad litoral articulada a través de territorios movidos se ilustrará a continuación mediante la descripción etnográfica de un mundo en movimiento, los relatos sobre movilidad humana y transformaciones del entorno, y algunas versiones acerca de la destrucción.

\section{Un mundo en movimiento: lunas, vientos, lluvias y mareas}

La Barra, a orillas del Pacífico vallecaucano, está dibujada por el perfil del litoral y su historia acontece amarrada al movimiento del mar, al ritmo que canta la marea. Asentada en la zona de transición entre la costa rocosa del norte y la llanura aluvial del sur, La Barra - vecina de Bahía Málaga (al oriente), de la desembocadura del río San Juan (al norte), de las puntas de Juanchaco y Ladrilleros (al sur) y del inmenso Pacífico (al occidente) — constituye un lugar de paso de flujos geográficos, biológicos, geológicos y humanos. Algo tiene de los acantilados que sobresalen abajo, en la costa chocoana, y de los pantanosos manglares que predominan arriba, en la franja caucana y nariñense. Abajo refiere los lugares ubicados al norte, a los que se llega con la corriente y el viento a favor. Arriba se sitúa en el sur, espacio al que se viaja contra el viento y la corriente. La confluencia del mar (movido por el viento, las corrientes y mareas) y la tierra (bañada por ríos, quebradas y esteros inundados de aguacero y sembrados de manglares), y la conversación profunda entre cortezas tectónicas, sedimentan y desgastan una forma de vida orillera $^{16}$.

En las playas de La Barra el mes se divide en cuatro mareas clasificadas como pujas y quiebras, dos de una y dos de otra, que se intercalan cada semana: una semana es puja y la siguiente quiebra. El primero de puja (primer día de esa marea) tiene la marea más baja y amanece vaciando, pero el agua cada día sube más. La quiebra comienza con la marea más alta (cabeza de agua), cuando el agua cabecea y empieza a menguar. La gente conoce bien los cambios entre pleamares (mareas altas) y bajamares (mareas bajas), y con ese movimiento se miden muchas actividades. El corte que hace el mar sobre la arena dibuja el límite al que llega en marea alta; los horcones (palafitos) de las casas se levantan por encima del nivel de las pleamares en puja y los navegantes identifican los bajos que sobresalen en el mar cuando baja la marea o los secaderos que impiden el tránsito por los esteros cuando el agua merma. En quiebra la amplitud es menor (más o 
menos las dos cuartas partes de la puja), el agua sube y baja menos; en puja es mayor, sube y baja más y con más fuerza ${ }^{17}$. La diferencia entre dos mareas máximas (el tiempo que toma el mar en rozar el punto más alto y ese mismo punto en la pleamar siguiente) es de doce horas y media. Si un día el agua sube hasta las 9 a.m. (y alcanza el máximo a tal hora), subirá de nuevo ese mismo día hasta dicho límite a las 9:30 p. m. y luego a las 10 a. m. Hay un tiempo neutro entre los cambios de marea: unos minutos en que el agua está quieta cuando está arriba, antes de bajar, y cuando está abajo, antes de subir ${ }^{18}$.

Explican los barreños que hay quiebras que parecen pujas y pujas que parecen quiebras. Cuando viene una puja grande (una vez al mes) se adelanta un día y sube seis días. Cuando es pequeña no avisa y dura ocho días. La puja grande siempre avisa; sin embargo, no lo hizo el día que se llevó las primeras casas en una madrugada a finales del 2013. Las mareas se mueven con la luna y pueden afectarse con los vientos. La puja coincide con la luna (plenilunio) y con la menguante (luna nueva, sin luna). La quiebra, con el cuarto creciente y el cuarto menguante. La luna, como la marea, se retrasa cada día. Por ejemplo, cuando es primero de puja y la luna está creciendo, se ve salir desde bien temprano (antes de las 6 p. m.) por el oriente. A los tres días - el cuarto día de puja - será plenilunio: el astro se dejará ver a las 6 p. m. y quemará hasta las 6 a. m. Desde ese día, menguando cada día, terminará saliendo a las 6 a. m. y las noches serán oscuras —sin luna-. Después, nueva la luna, empezará de nuevo a crecer. Tanto la luna como la menguante pueden ser hembra, cuando es clara la noche, o macho cuando es oscura. Cuando la menguante o la luna no han terminado de definirse es que no están jechas, les falta madurar.

La pesca en los esteros, llamada pesca por dentro ${ }^{19}$, y la recolección de piangua (Anadara tuberculosa) son convenientes en puja: la fuerza del agua saca el molusco a la superficie y el empuje de la marea lleva pescados y camarones al estero. En el manglar, en medio de las raíces, se esconde la piangua, que debe cogerse cuando el agua está seca, en bajamar. En puja, mujeres pescadoras y piangüeras salen en media vaciante (el agua amanece bajando) para llegar al manglar con el agua seca y estar de regreso en media marea, cuando empieza a llenar. Si amanece secando a las 6 a. m., las embarcaciones pueden zarpar a las 9 a. m. e

17 Las quiebras también se conocen como "mareas muertas" o "de cuadratura" y las pujas, como "mareas vivas" o "de sicigia" (Ideam 2014). (2009). 
iniciar el regreso a eso de las 3 p. m. El corte de madera también depende de la conversación entre el mar y la tierra: para transportar las trozas desde el monte se necesita la lluvia y la marea, pues la empalizada en que flotan los troncos es empujada por el agua. Si no llueve ${ }^{20}$, las quebradas que sirven de vía de transporte no crecen; si la marea no sube, los esteros no se llenan y con la marea en contra es difícil viajar en la corriente: hay que esperar el aguacero, el flujo y el reflujo de la marea ${ }^{21}$.

La madera debe cortarse en menguante, cuando las noches son oscuras. $\mathrm{Si}$ se corta en luna, los palos se dañan fácilmente porque la bruma — una especie de polilla - pudre y debilita las trozas. En la costa, otra bruma - o llublina, mezcla de lluvia y neblina-impide ver las señales (montes, palos, piedras) que indican dónde pescar en el mar y los pescaderos (lugares de pesca) se pierden en la inmensidad. A los peces no les puede dar la luna porque se pudren, se alunan. La pesca nocturna, sin embargo, es mejor en luna, en noches iluminadas. En menguante la oscuridad ilumina el mar: con el movimiento de las embarcaciones, los canaletes, el nailon y la malla, el plancton hace prender el agua y el brillo espanta los peces. La cacería, en cambio, es mejor en menguante porque en la noche oscura los ojos de los animales brillan con más intensidad: en menguante el animal da ojo.

Los vientos más fuertes en La Barra son el sur, el sueste y el weste. Quien viaja de sur a norte va con la corriente y lleva el viento en la popa: navegar en ese sentido es bajar con el mar y con el aire. El tiempo (el viento) manda en la pesca y en la navegación, desentierra los árboles y enfurece al océano. Las marejadas -el empuje del mar que cubre la costa - nacen de los fuertes vientos y de las tormentas. Con los vientos y corrientes viajan pelícanos, pescadores y sardinas (alimento de las aves y peces grandes). Los pájaros son la guía, la ruta hacia la carnada: la abundancia de sardinas en el mar se refleja en la concurrencia de pelícanos en el cielo y de embarcaciones en el agua. Son buenas épocas de pesca para el pueblo.

En el encuentro de la selva y el océano median los manglares surcados por ríos y por esteros. Las bocanas se abren de los ríos al mar, los esteros penden de las bocas y las quebradas de los esteros. En La Barra estos forman un paisaje laberíntico: El Chorro, La Islita, Coquero, Cementerio, Pachive, Chucheros,

20 Hay que mencionar la importancia de la lluvia más allá del transporte de madera. En La Barra, caserío que no cuenta con acueducto, el agualluvia tiene un uso doméstico, además de incidir directamente en el paisaje. Los esteros y quebradas crecen o secan dependiendo de los ciclos pluviales y, así mismo, repelen o admiten el empuje de la marea. Por otra parte, las labores diarias se limitan cuando el tiempo está malo por los aguaceros. 
Chucheritos, Caecae, Madrevieja, Sardineras, Quebrada del Medio, Barradentro y Sabaletas son algunos de esos callejones acuáticos, estrechos y enrevesados por los que se mueven los barreños en canoas hechas de los árboles que crecen en sus orillas. El inmenso río San Juan, cuyas aguas brotan de las alturas andinas a 400 km de su llegada al océano, traza al norte de La Barra el límite geográfico con el Chocó y su delta es también un laberinto: Bocas de San Juan-El Choncho, Chavica, Cacagual, Charambirá, Togoromá, Pichimá y Venado forman el entramado de sus salidas al Pacífico.

Figura 2. Giovanni, de trece años, navega un estero que conoce desde los cinco, edad en que su madre le enseñó a pianguar en el manglar

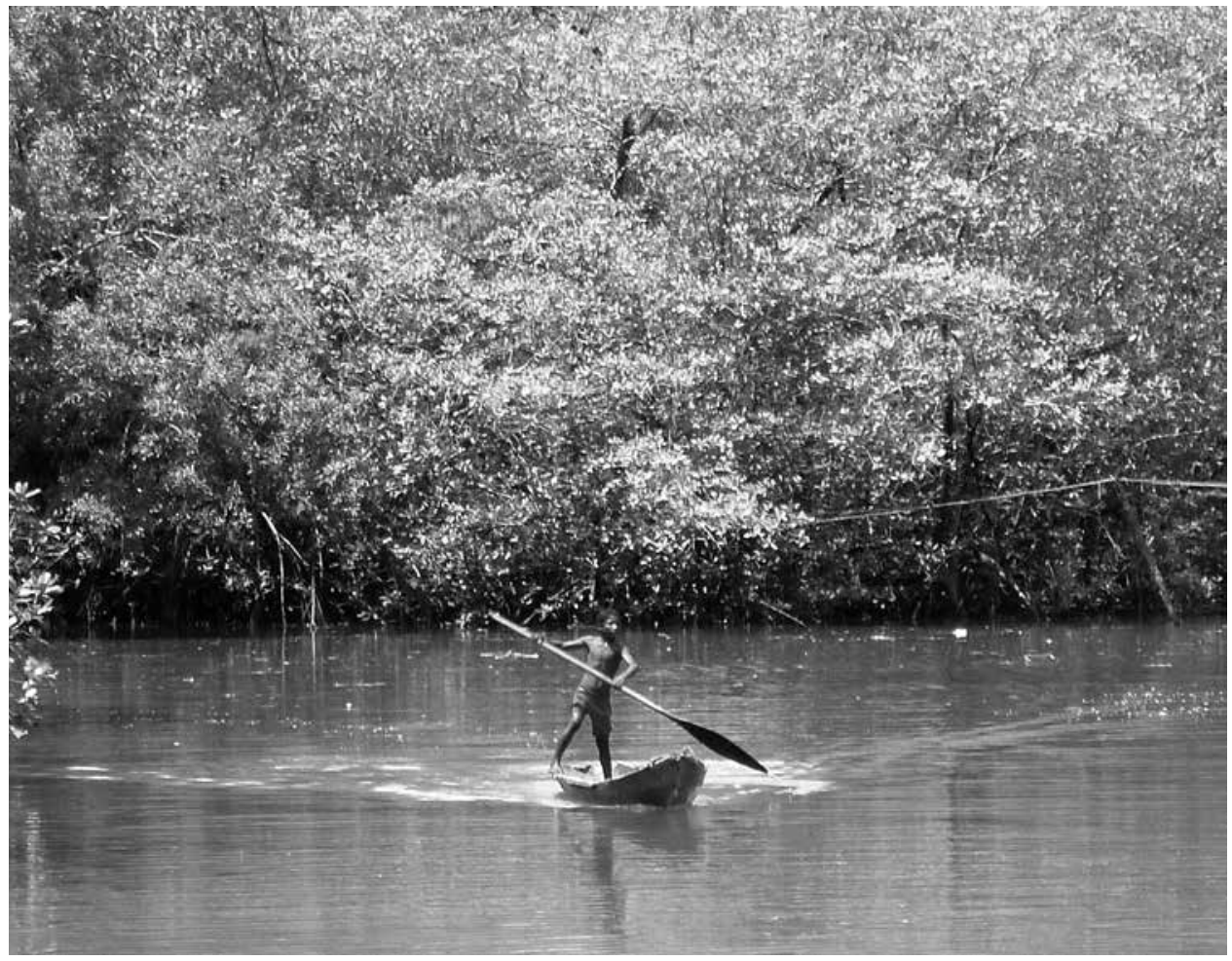

Fuente: archivo personal de la autora, julio del 2016. 


\section{Movilidad humana y transformaciones del entorno}

Hace setenta años, cuentan los actuales pobladores, llegó la gente negra a La Ba$\mathrm{rra}^{22}$. Como lo vieron los mayores, padres y abuelos de los ahora veteranos, el espacio ocupado actualmente por el pueblo era dominio del monte y del océano. La playa quedaba más al norte, justo donde ahora parece estar formándose de nuevo, y el mar chocaba contra las peñas que se levantan detrás del espacio en que la gente ha ido moviéndose conforme la marea se acerca o se distancia. Las canoas salían y entraban al mar por un canal que bordeaba la montaña, la tierra firme. Todo lo que es arena era entonces agua. Después, hace cincuenta años, se dibujó la playa que el mar insiste hoy en reclamar.

Casimiro Díaz Santiesteban llegó de Bahía Málaga estando muy tierno, pero se acuerda todavía de los viajes que hacía desde la desembocadura del San Juan hasta Buenaventura. Afirma haber conocido una playa grandota, ubicada al norte de La Barra, que después de un tiempo desapareció. Entonces, la arena, robándole terreno al mar que lavó en otro lugar la tierra, formó la playa que existía hasta hace algunos años. La arena que se pierde en un lado no se acaba, asegura Casimiro, esa arrima a otro lado. Conoció La Islita cuando tenía 9 años, hoy tiene 57. Hace 48 años vio la playa que luego se llenó, y ahora otra vez está cogiendo forma. Esto confirma lo que él piensa: cada cincuenta años las playas $a$ bordo de mar se transforman, por eso se está yendo la de La Barra. El mar recobra lo que es suyo:

Sí, pues dicen que las playas así, a bordo de mar, cada 50 años, si se han ido, recobran su arena. Tengo como experiencia La Islita. Esa playa iba desde aquí arriba, desde las quebradas, y llegaba hasta allá, a la entrada de Barradentro. Me fui pa Málaga y cuando después de un tiempo volví por acá ya no estaba más. Pero ahora veo que la arena que se está perdiendo de acá está formando el playón a como era la playa a ese lado. Entonces, digo yo, ¿por eso no será que se está yendo la playa de La Barra? El mar recobra lo que era de él. (Testimonio de Casimiro. Entrevista realizada en julio del 2016)

Plácido Salazar Pretel tiene 60 años y recuerda que a los 7 llegó con su familia a esta playa. Su padre — también llamado Plácido y pescador-decidió

22 Uso la categoría gente negra porque responde a la denominación local de los barreños, quienes se dicen a sí mismos negros o libres. Por otra parte, esta investigación no pone el énfasis en las articulaciones con el legado africano que suponen categorías como afrodescendiente o afrocolombiano. 
que se establecerían en el incipiente caserío. Antes de eso vivían en Bocas de San Juan, donde la vida también dependía de la pesca. Un día lanzaron sus anzuelos y la suerte los acompañó: además de sacar buen pescado lo vendieron rapidito a unos turistas que por esa época ya visitaban la playa. Al ver que podían ganarse la vida mejor que en el San Juan, decidieron quedarse y construir su casa en La Barra. En ese entonces unos pocos ranchos ocupaban La Rotura, como afirma que se llamaba originalmente La Barra. Según Plácido, la gente dice que esto es La Barra, pero antiguo era La Rotura. Y recuerda que "esta playa era más inmensa. Más inmensa esta playa era”.

"La Rotura" quizás responda a una entrada de agua sobre la que después predominó la barrera costera. La Rotura y La Barra son denotaciones acuñadas por un mar que rompe y forma playas, y por la imaginación humana que las apropia y significa. "Playa Alta” y “Playa Baja” — topografías posteriores a la destrucción del caserío en el 2014- designan el terreno que inundó la marea y aquel que permaneció seco. Los lugares y sus nombres actúan sobre la historia del espacio y revelan los vínculos que la gente tiene con las características geográficas. El lenguaje se despliega en el paisaje que, nombrado, forja un sentido de lugar y una forma íntima de habitar (Basso 1996).

Las familias fundadoras - que abrieron monte, construyeron ranchos y sembraron la tierra- venían de playas chocoanas y de ríos que nacen en la cordillera Occidental y alimentan con sus aguas el océano Pacífico. Los Mosquera llegaron del bajo San Juan; los Rivas de Nóvita, famosa por sus minas; los Manyoma del río Calima, afluente del San Juan; los Díaz de Málaga, que linda con el oriente de La Barra. Los Murillo vinieron del Choncho, los Pretel de Chavica y los Salazar de Concheros: playas formadas por el delta del caudaloso San Juan. Migraciones recientes, forzadas y deseadas, han contribuido también al crecimiento del pueblo. Hombres y mujeres provenientes del Naya (río vallecaucano que descarga sus aguas al sur de Buenaventura), de Mosquera (municipio costero de Nariño) y de Arusí (playa chocoana) se han establecido en La Barra. Además del empuje del mar, la progresiva ocupación de estas tierras ha estado guiada por diferentes auges económicos: la tagua (Phytelephas aequatorialis), la madera, la corteza de mangle (Rhizophora mangle), la pesca y el turismo impulsaron la colonización del territorio y orquestaron la organización del espacio ${ }^{23}$. No es esta, sin embargo, la historia de unos seres gobernados por el mar y por los ritmos

23 Es importante resaltar que algunos investigadores muestran cómo la guerra ha reconfigurado el espacio en geografías del terror (Oslender 2004) y de qué manera el conflicto y el desarrollo han modificado radicalmente los paisajes biofísicos y culturales (Escobar 2004) en el Pacífico colombiano. 
extractivos: es el relato de vidas “andariegas” y orilleras que caminan el océano y se aventuran en otras tierras por azar o necesidad, por conflictos y por amor, por buscar mejores pescas o encontrar con quién hacer la vida.

Amable Rivas Mosquera, hijo de Epifanio y primo hermano de Plácido, nació en 1951 y recuerda haber crecido en la finca de su familia en Barradentro, lejos de la playa. Vivían de sembrar papachina, plátano, piña y caña, con la que su madre hacía guarapo. En esa época, hace más de 70 años, no había turismo y en Juanchaco - la localidad más poblada de la zona - solo vivían diez familias. A la costa solo iba a pescar o a sacar corteza del manglar de la que se extraían taninos para teñir ${ }^{24}$. En eso trabajó hasta los catorce años. Él se crio, según dice, en el corte de madera ${ }^{25}$; no conoció la tagua pero supo que sus viejos la menta$b_{a n}{ }^{26}$. El aserrío del San Juan existía cuando Amable nació y se acabó a finales del siglo pasado. Hace 44 años se trasladó definitivamente a la playa. Este hombre, quien dice ser de monte más que de mar, vivió su juventud trabajando para el aserradero. Su fundador, Ricardo Álvarez, don España, fue un extranjero que se estableció en el lugar y bautizó con su nombre a Puerto España, antes conocido como Bocas de San Juan ${ }^{27}$.

De los árboles más apetecidos, dice Amable, "ya no queda ni la semilla”, se acabaron con tanta aserradera. Cinco o seis máquinas trabajaban a la vez y los esteros se aturdían con el ruido de las motosierras. Los animales del monte se espantaron con ese destrozo del bosque. Antes se veían más guaguas, armadillos, zorras, tucanes, loras y leones. Recuerda que, cuando vivía en la finca, los tigres y caimanes abundaban porque en la región no había casi gente. Los animales se acabaron porque de Buenaventura llegaban a cazarlos. En 1959, según Amable, gente de fuera construyó el primer hotel en Juanchaco. En ese entonces solo diez

Robert West ([1957] 2000, 240) refiere que desde la segunda década del siglo pasado se registraban campamentos de cortadores de mangle e importantes estragos en el manglar. Sin embargo, fue a finales de la década de los cuarenta, como antesala del corte intensivo de madera, que "comenzó la explotación en grande de los manglares de la costa para la extracción de su corteza" (Leal y Restrepo 2003, 55).

Claudia Leal y Eduardo Restrepo (2003) describen cómo la extracción de madera comandó la organización del espacio a lo largo del litoral. La explotación de los "bosques sembrados de aserríos" introdujo transformaciones abruptas en el ambiente y en la forma de vida de los pueblos pacíficos desde la década de los cuarenta del siglo XX.

La tagua es una semilla que sirvió como reemplazo del marfil de elefante en la fabricación de botones antes de ser sustituida por materiales sintéticos en 1930. Pobladores negros e indígenas del Pacífico sur y del Chocó vivieron de recolectarla por casi ochenta años (West [1957] 2000, 236). Esta actividad, propia de una economía selvática, incentivó el control territorial y la autonomía laboral por parte de los trabajadores negros (Leal 2008). 
familias habitaban el lugar y se dedicaban a la pesca, la siembra y la madera. Con el turismo, quienes vivían en el monte, en tierras firmes donde el mar no molesta, se desplazaron a las playas porque la plata se cogía mucho más fácil con los foráneos que llegaban a divertirse. Hasta esos años, insiste Amable, los tiburones abundaban cerca de la costa. Desde la playa se veían las aletas deambular por el mar.

Dominga Hinestroza, hija de la región del Naya, llegó a La Barra hace 25 años. Recuerda que cuando conoció la playa en Playa Alta (el extremo sur del pueblo) el monte estaba bajitico, apenas creciendo. Playa Baja, arrasada por el mar en el 2014, estaba grandota. "La playa, como va, viene”, afirma. En su juventud partió de Puerto Merizalde (pueblo fluvial asentado en los límites entre el Valle y el Cauca) hacia Isla Mono (en el Chocó, San Juan arriba) y el río Bongo, tributario del San Juan. Cuenta que antes de establecerse en la playa trabajó muchos años "trozando madera, rozando y tumbando el monte por donde pasan los palos hacia la marea”.

Antonia Valencia Díaz, hermana de Eduvina (esposa de Plácido) y prima hermana de Casimiro, nació en Bahía Málaga hace 57 años. Cuando tenía 7 se trasladó con su familia a las playas de La Barra, en ese entonces conocida como La Rotura. Viajaron a este lugar porque su padre, Manuel Santos Valencia, quería trabajar en la troza y aquí estaría más cerca del aserrío. El hombre se dedicó a sacar madera del Bongo y del San Juan hasta que una $X$ lo mató, estando él todavía entero ${ }^{28}$. Antonia recuerda que cuando llegó a las tierras de La Barra todo lo que ahora es arena en Playa Alta era entonces mar; la playa de Ladrilleros — de la que ya no queda casi nada - era inmensa, toda sembrada de cocotales. En ese tiempo el viaje a la bahía de Málaga se hacía por dentro, por los esteros y la tierra firme que se levanta después del manglar, que eran más transitados. No existían lanchas de motor y los navegantes se movían a viento y marea, con velas y canalete. Antiguo, el viaje a Buenaventura tardaba ocho días; las embarcaciones tenían que hondiar (anclar) donde les cogiera la noche y esperar los vientos para seguir el camino. Los motores, que aparecieron en La Barra “como en 1956”, eran tan raros como los aviones que acuatizaban en el Bongo y en Bocas de San Juan.

Desde 1980 se puso pesado el trabajo de la madera ${ }^{29}$ y la gente se dedicó más al turismo. En las décadas que cerraron el siglo pasado, recordadas por los

28 En La Barra, la X y la verrugosa son culebras vengativas que buscan o esperan a quien las ha toreado. Estas, como las visiones del monte, constituyen una forma de mediación entre la comunidad y una selva que se venga de los excesos humanos.

29 Leal y Restrepo (2003) afirman que la fase intensiva del corte de madera en la región del bajo San Juan terminó hacia 1975 y la extracción de la corteza de mangle se clausuró a comienzos de 1980 . 
barreños como una época dorada, abundaba el dinero en estas playas porque los duros del Valle venían a divertirse. Juanchaco, Ladrilleros y La Barra fueron escenarios en los que la bonanza del narcotráfico se vivió como un auge del turismo. Desde el 2014 este último se ha visto afectado por la desaparición de las playas. Además, la infraestructura que hace posible el turismo a gran escala, tal como lo imaginó el sueño regional de tener un "balneario del Pacífico" ${ }^{30}$ en las playas de Ladrilleros y La Barra, es, desde el punto de vista local, una de las causas de la destrucción ${ }^{31}$.

A partir de estos relatos se puede afirmar que distintos ciclos productivos han caracterizado la historia de La Barra. Sin embargo, la pesca artesanal y la recolección de piangua han permanecido como base de la economía local. Plácido, cuya familia se trasladó a La Barra gracias a la abundancia de peces, afirma que la pesca también se ha dañado en los últimos años por tanta competencia: barcos extranjeros sacan hasta 13 toneladas de pargo (Pagrus pagrus) con mallas que arrasan con todo, mientras en un buen día de pesca una lancha local obtiene 200 o 300 libras $^{32}$. Los viento y marea, embarcaciones que vienen de Buenaventura, representan también una competencia que está acabando con la comida. Son tantas lanchas que, de noche, “el mar parece un pueblo de pescadores”. Además de llevarse el pescado, enredan sus redes en las rocas y destruyen los nichos en que habitan los animales. El pargo, el pez más apetecido en La Barra, es roquero: se encuentra en las rocas que sirven de pescaderos.

El declive de la pesca inició, según algunos, con la caída de las Torres Gemelas de Nueva York en el 2001. Esta versión podría estar asociada con el fin de la época dorada de los narcos y el turismo, además del bombardeo mediático que posiblemente fecundó la idea de que la vida propia tenía que ver con el evento, la sensación de ser parte de un mundo conmocionado. Esta interpretación sobre el ocaso de las buenas épocas de pesca y de los años dorados del turismo da pistas

La Ley 55 de 1966 declaró "el fomento del turismo y la colonización en la costa del Pacífico" como parte de un proyecto que cedía los "baldíos" de la Nación al departamento del Valle del Cauca. Véase www.valledelcauca.gov.co/etnicos/descargar.php?id=17540.

31 Desde hace aproximadamente un año, los pobladores de La Barra impulsan un turismo comunitario que se distancia profundamente de aquel proyecto foráneo que soñaba con el "progreso" de la región. Sin grandes hoteles ni carreteras de concreto, ofrecen a los visitantes la posibilidad de conocer La Barra a través de una mirada local que los mismos barreños han imaginado.

32 El uso de mallas camaroneras de ojo muy pequeño, que no respetan el tamaño de los animales ni discriminan especies, intenta ser regulado en La Barra. La pesca intensiva con trasmallos electrónicos (de ojo diminuto) ha causado importantes impactos ambientales e implicaciones sociales en el Pacífico vallecaucano (Motta y Perafán 2010, 49). Por otra parte, el fenómeno de El Niño aumenta la temperatura del agua y estimula la migración de peces hacia otras latitudes o profundidades, lo que redunda en pérdidas para las economías pesqueras locales (Leyva 2003, 149). 
sobre cómo las comunidades asumen su conexión con el mundo, cómo se ubican frente a una economía política de la cual se sienten damnificados.

A propósito de dicha conexión, puede intuirse que los ciclos productivos amarran La Barra a un contexto global tanto como lo hace la erosión costera. Entre otras cosas, algunos barreños afirman - especialmente quienes están involucrados con el proceso organizativo del consejo comunitario- que el cambio climático es una de las razones de tanto desastre e insisten en el carácter resiliente de La Barra. Según el saber “experto”, el cambio climático causado por el calentamiento global atmosférico transforma las dinámicas oceánicas afectando los ecosistemas marinos y la línea de costa por erosión e inundaciones (Leyva 2003, 138). Así, el mar conecta la Tierra a través del calentamiento "global” que sube el nivel del agua y toca todas las costas del mundo (aunque afecte más a unos pueblos que a otros), o de barcos que surcan el océano cargados de oro, pescado, tagua, madera y cocaína.

\section{Sobre la destrucción: entre arenas juguetonas y azogues que seducen}

En los últimos años, las dinámicas de reconfiguración espacial antes experimentadas se tradujeron en la desaparición de gran parte del caserío con las devastadoras pujas de enero, abril y septiembre del 2014. Eduvina Valencia recuerda que en la noche del 31 de diciembre del 2013 el mar empezó a llevarse las casas. El corte del día anterior indicaba que el mar no tocaría las casas, sin embargo, aquella madrugada el agua llegó y La Barra quedó dividida en dos caseríos: Playa Alta y Playa Baja. Las familias amanecían en la selva buscando refugio, lejos de los temidos cables eléctricos y de las rabietas de un mar que estaba recuperando terreno. Lo que más temían era que se derrumbaran los postes de energía. El mar partió la playa y esta al pueblo. La ruptura física engendró una escisión social; quien vive y trabaja en uno de los extremos rara vez se desplaza hacia el otro lado.

El mar amenazante no es exclusivo de épocas recientes. Cuentan los viejos que antes hubo mar donde ahora hay playa y es posible que pronto el agua recupere la tierra perdida. Casimiro afirma que las costas se revolucionan cada cincuenta años y describe una cíclica formación y destrucción de playas. Como hoy está sucediendo, la arena que el mar se lleva es devuelta en otros lugares y, así mismo, algún día retornará al espacio del que se va ${ }^{33}$. Explica que la arena

\footnotetext{
33 Algunos barreños afirman que la arena que se está yendo de su playa está formando otra más al norte. El testimonio de Casimiro enseña que La Islita, desaparecida hace casi cincuenta años, está recobrando su forma con arena que se va de La Barra.
} 
es juguetona porque, a diferencia del cemento, “está viva, se mueve sola”: un día está y después ya no. Amable piensa que con "los cambios que da el mar” y los "jenómenos de la naturaleza" las playas se van y otra vez llegan. La arena de La Barra no se ha ido, "tiene que estar dando vueltas por aquí".

Plácido asegura que el cemento se lleva la playa. Cuenta que hace años instalaron unos tanques de concreto para que hicieran las veces de pozo séptico. La idea llegó con un proyecto del Gobierno y, a pesar de que muchos se negaron a aceptarlo, otros permitieron que el cemento fuera enterrado en la arena. Años antes, también el Gobierno había propuesto construir casas de material pero nadie aceptó porque es sabido que el mar busca el cemento. Este, según dicen en La Barra, tiene azogue, sustancia que atrae el aguasal y ejerce el efecto de un imán que llama al mar... y al oro también ${ }^{34}$. Seducida por el azogue del cemento, llegó la marea y desenterró lo demás.

Dominga corrobora que el cemento tiene imán: "el mar no puede ver cemento" porque se lo lleva y la marea no descansa antes de comérselo. Amable también insiste en que no se pueden fabricar casas de material en la arena porque el azogue hace ir la playa. Alega que, como es playa turística, la gente quiere construir en concreto pero "el mar no quiere nada con el cemento". Desde que llegaron los hoteles - hechos de cemento- a Juanchaco y Ladrilleros, el mar empezó a comerse la arena. Plácido recuerda que antes del turismo las cosas eran muy distintas, ya que la gente se dedicaba a otras actividades. "Desde el turismo todo se acabó”, sentencia. Los barreños viven en la tensión de aceptar el turismo que es una actividad rentable y rechazar el cemento que destruye sus playas ${ }^{35}$.

Las explicaciones esbozadas en este apartado dan cuenta de cómo los barreños entienden su devenir imbricado con el vaivén de la marea y los juegos de la arena. Un movimiento agita el espacio y la vida que en él se despliega. En este inquieto mundo la destrucción es a la vez creación. Las formas de habitar describen una oscilación que marcha al ritmo del mar tanto como lo hacen las actividades productivas locales. Las semanas de puja y de quiebra, las horas de vaciante y de marea escriben un tiempo movido por el flujo de la luna, la fuerza del viento y el impulso del océano. La Barra, dicen algunos barreños, es un pueblo de caminantes que corren en el agua y que al son de sus migraciones formaron el caserío.

34 Azogue es el nombre con que se conoce el mercurio en la minería. Es sabido que este, usado para minear en muchos lugares de Colombia, envenena cuerpos y geografías. Popularmente, azogarse es agitarse mucho: el mar se desespera, se inquieta y tiembla frente a las playas cubiertas con cemento. que para ellos resulta destructiva, ni deja en manos ajenas - como en el caso de los grandes hoteles- las ganancias que conlleva la actividad. 
Figura 3. Concreto sembrado en las playas de La Barra amenazadas por el mar

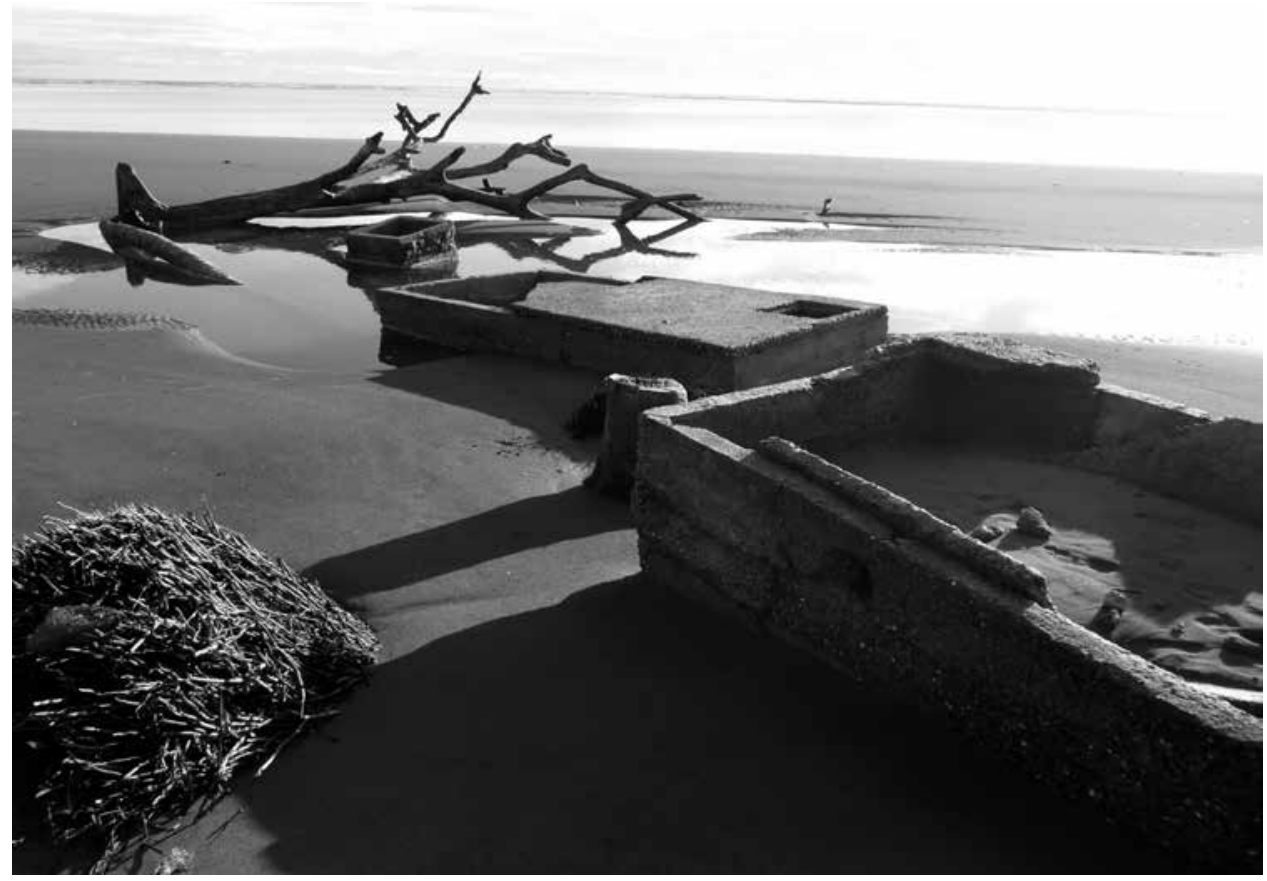

Fuente: archivo personal de la autora, julio del 2016.

Por otra parte, la presencia del cemento en las playas del Pacífico podría pensarse como una proyección del progreso ${ }^{36}$ que produce una espacialidad moderna mediante la destrucción de ciertas gentes y geografías, dejando una estela de ruinas y desolación (Gordillo 2014). La introducción del concreto petrifica la plasticidad constitutiva de la interacción de algunos pueblos con el mundo: pueblos "andariegos" habitantes de paisajes movidos e inestables que construyen sus casas sobre palafitos que aguantan la sal y el empuje del mar. Casas flexibles que pueden desenterrarse y sembrarse en otro lugar, hechas de troncos que la selva proporciona. El cemento, en cambio, no puede moverse, no está vivo como la arena o los horcones de mangle que se entienden con la marea. En su quietud es lentamente roído por el mar que eventualmente lo tragará.

Desde la década de los sesenta del siglo pasado la madera ha sido desplazada por el cemento en la costa pacífica colombiana. Como señala Motta (1998), este último constituye un "elemento modernizador" que "significa estabilidad, estatus, poder y relaciones con la política externa", y representa "la posibilidad de integrarse al proyecto moderno de las ciudades andinas" (50-52). El sueño de pueblos urbanizados sustituye los materiales endógenos por pilotes de concreto que no resisten las inundaciones ni la humedad (Mosquera 1993). 
Después de las pujas del 2014 los barreños afirman que la vida se ha dificultado. "El tiempo está pesado”, comenta Eduvina. Ella, que es partera y ha sido testigo de la abundancia de niños en la localidad, piensa que tener hijos en este momento es "pasar mucho trabajo". Hoy en La Barra no se ven tantos bebés ni mujeres embarazadas como solían verse; muchas están planificando para evitarlo. La mayoría de gente tuvo que levantar su casa en el viejo pueblo para trasladarse a Playa Alta o internarse un poco más en la selva. Algunos han decidido desplazarse definitivamente a una loma que no está a merced de la marea, pero cuya ubicación dificulta las actividades que tienen que ver con la playa y el mar, como la pesca y el turismo; es el lugar destinado para el nuevo pueblo. En medio de la dificultad los barreños aceptan los designios del mar y los enfrentan con dignidad. Una fuerza creadora desmiente la destrucción. La transformación puede rehacer el mundo y ser una invitación para crear lo nuevo (Gordillo 2014, 264). El profesor del pueblo, Eliécer Posso, afirma que La Barra tiene una capacidad de resiliencia impresionante. La constante reconstrucción del caserío y el fortalecimiento de la organización comunitaria son evidencia de ello.

Los elementos que señalan la configuración de La Barra al compás del movimiento del mar y de la cercanía con la selva, del corte de madera y de mangle, de la pesca y el turismo, abordados en esta historia del cambio hecha de migraciones humanas y mutaciones del espacio, de vidas movidas y entornos cambiantes, permiten vislumbrar aspectos de carácter social, político y económico desplegados en la transformación del paisaje (Leal y Van Ausdal 2014). Ilustran, además, el encuentro del devenir humano con una naturaleza en rotunda transformación a través de una interacción conflictiva mediante la cual la tierra se moldea en tanto los seres humanos se realizan y modifican (Palacio 2002). En una suerte de dialéctica ecológica, la relación entre humanos y naturaleza esculpe la historia humana y trastorna la historia de un mundo en constante recreación. En ese sentido, la desaparición y formación de playas pueden entenderse como dinámicas hermanadas que perfilan una destrucción creadora.

\section{Consideraciones finales}

En algunos lugares del Pacífico colombiano el entierro de la placenta y del cordón umbilical ata los hilos de la existencia individual al territorio, mientras el contacto del recién nacido con una sustancia animal, vegetal o mineral fecunda 
una relación vital ${ }^{37}$ que sella el vínculo telúrico. En La Barra cuentan que el dolor de los huesos anuncia la lluvia y que el mejor sobador es también carpintero. El humor fortalecido de la mujer embarazada es capaz de matar serpientes; el del hombre que ha tenido sexo en la noche lo expone al encuentro con la víbora al día siguiente. El aprendiz de curandero tiene que comer carne y huevos de culebra: asimilar el animal para contrarrestar con su propia fuerza el veneno, como con el suero, que está hecho de veneno. Hombres y mujeres tejen casas en las que viven y mueven su mundo atendiendo a la cadencia del océano. Este tejido es el soporte de la vida y su textura aprieta las existencias imbricadas de los seres y elementos que lo zurcen.

Este acercamiento etnográfico apoyado en la historia ambiental ha permitido ilustrar cómo las vidas movidas y los paisajes cambiantes trazan formas de habitar que, en estrecha intimidad con el agua, articulan configuraciones territoriales en permanente construcción. He presentado una perspectiva iluminada por una tierra en movimiento en la que las comunidades y los territorios se coproducen con un entorno cuya incesante alteración actúa sobre las maneras en que la gente habita y concibe el mundo. Una trama telúrica que imita la forma laberíntica de los manglares y se mueve al ritmo de las mareas amarra la humanidad al perfil y las conmociones de la tierra. A través de los relatos sobre un territorio forjado en la inestabilidad y el movimiento, he querido mostrar este tejido urdido en la conversación humana con fuerzas geológicas y atmosféricas que conjura la separación de los seres humanos y la naturaleza y defiende la posibilidad de hacer la vida en un lugar particular del mundo.

Los rasgos descritos dan cuenta de una territorialidad caracterizada por una movilidad continua parecida al movimiento del mar y de la tierra que configura una forma de habitar en diálogo con las agitaciones telúricas. La capacidad de rehacer la vida, de levantar una y otra vez el caserío conforme la marea lo permite, ilustra una plasticidad que emula —o es imitada por — la dinámica de la tierra. La reconstrucción del pueblo, a pesar de los costos que conlleva, se concibe como algo propio del movimiento de la vida. Los barreños viven con la transformación y el cambio es constitutivo de un mundo hecho de "playas activas”, de barreras que el mar forma y destruye. La devastación, sin embargo, no deja de ser un evento desastroso para quienes viven en medio de la incertidumbre creada por la latencia destructiva.

37 Véanse Losonczy ([1997] 2006, 194-196) y Arocha (1999, 15-16). Por su parte, Luis Guillermo Vasco (2010) relata cómo los indígenas guambianos del suroccidente colombiano entierran su cordón umbilical en las cenizas del fogón del lugar donde nacen, amarrándose así a su origen: "dicen que se trata de un hilo que ata a cada guambiano [...] y teje su historia" (s. p.). 
Sin ser el enfoque de esta reflexión, no he pretendido desconocer las profundas desigualdades, determinadas muchas veces por singularidades étnicas y de clase, que actúan en la manera en que algunas gentes y geografías sufren el embate de la naturaleza. En La Barra, la destrucción de mares, playas y selvas por acción del cemento, la motosierra y la pesca predatoria parecen rasgos de una modernidad que se abre camino violentamente a través de una producción destructiva (Gordillo 2014). Es posible pensar que en este lugar la destrucción se agudiza, entre otras cosas, por los efectos de un proyecto geopolítico que desatiende las urgencias de quienes reclaman, como los barreños, ser desplazados del mar. Algunos recuerdan cómo padecieron la ausencia de ayudas oficiales, pues lo único que recibieron de la Gobernación del Valle fueron viajes de madera podrida y la propuesta de una titulación individual de su territorio antes de que el título colectivo fuera otorgado. Por otra parte, los enviones del mar que amenazan a la comunidad negra de La Barra están asociados con fenómenos meteorológicos ligados al cambio climático que resulta de un calentamiento "global" que, sin embargo, golpea más fuerte a poblaciones "prescindibles" o a quienes no tienen la fortaleza económica e institucional para afrontarlo. El aumento del nivel del mar afecta directamente a pueblos mareños como La Barra, que sufren la transformación de los ecosistemas marinos y el avance de la línea costera sobre el continente.

La fuerza de la luna agita un mar que fluye al son de vientos y corrientes y en el que nadan peces cuya estela persiguen los pájaros que son la ruta del pescador. El océano se amarra a la tierra con el nudo laberíntico que tejen los esteros y los manglares sembrados de árboles, transitados por piangüeras, animales y visiones. La selva, surcada por ríos y quebradas inundadas de aguacero, se empapa con el agua salada que trae el impulso de la marea. Los barreños entienden esta trama en movimiento y conversan con las rabietas de un mar celoso y caprichoso en el que las olas ríen y mueren; con un tiempo (viento) que se emputa y una arena juguetona que, a diferencia del cemento, está viva. Ocupan y trabajan la tierra al ritmo de una marea que puja bajo el influjo de una luna que prende el mar y los ojos de los animales. El pescador pelea con peces visajosos y los troceros temen a culebras vengativas.

El amarre telúrico (histórico y contingente) puede rastrearse en este diálogo que los habitantes de La Barra sostienen con su entorno en un encuentro íntimo en el que no solo los humanos son agentes de la historia. Dicha intimidad entiende el movimiento de la vida que dibuja la formación del territorio y concibe la destrucción como una revolución cíclica de playas cuya arena circula, desperdigada, por otras playas. Tal proceso otorga voz a los flujos de materia y 
energía “que los seres humanos tenemos en común con las rocas y las montañas” (De Landa 2011, 29), y anima a pensar en el mar como fuerza acuática de la historia. El ímpetu del océano, la sedimentación de los ríos, los fenómenos climáticos, la erosión de los acantilados y los estremecimientos sísmicos, tan frecuentes en el Pacífico colombiano, se entretejen con las actividades humanas y sedimentan una historia telúrica hecha de conmociones destructivas y creadoras.

\section{Referencias}

Aprile-Gniset, Jaques. 1993. Poblamiento, hábitats y pueblos del Pacífico. Cali: Ediciones Universidad del Valle.

Arocha, Jaime. 1999. Ombligados de Ananse. Hilos ancestrales y modernos en el Pacífico colombiano. Bogotá: CES; Universidad Nacional de Colombia.

Basso, Keith. 1996. Wisdom Sits in Places. Landscape and Language among the Western Apaches. Nuevo México: University of New Mexico Press.

Castillo, Norma Constanza y Doris Alvis Palma, coords. 2003. El mundo marino de Colombia: investigación y desarrollo de territorios olvidados. Bogotá: Universidad Nacional de Colombia; Remar.

De Landa, Manuel. 2011. Mil años de historia no lineal. Ciudad de México: Gedisa.

Escobar, Arturo. 1999. El final del salvaje. Bogotá: ICANH; Cerec.

-. 2004. "Desplazamientos, desarrollo y modernidad en el Pacífico colombiano". En Conflicto e invisibilidad. Retos en los estudios de la gente negra en Colombia, editado por Eduardo Restrepo y Axel Rojas, 53-72. Popayán: Universidad del Cauca.

- 2014. Sentipensar con la tierra. Nuevas lecturas sobre desarrollo, territorio y diferencia. Medellín: Unaula.

Galindo, María Isabel. 2012. "Perdida en el monte encantado. Santos, infieles y tundas. Un camino entre los Andes y el mar”. Tesis de pregrado, Departamento de Antropología, Universidad Nacional de Colombia, Bogotá.

Gallini, Stefania. 2012. "La naturaleza cultural de la historia ambiental y su rematerialización”. En Historia cultural desde Colombia. Categorías y debates, editado por Max Sebastián Hering Torres y Amada Carolina Pérez Benavides, 377-397. Bogotá: Pontificia Universidad Javeriana; Universidad de los Andes; Universidad Nacional de Colombia.

Giraldo, César Enrique. 2009. Ecos en el arrullo del mar. Las artes de la marinería en el Pacífico colombiano y su mímesis en la música y el baile. Bogotá: Ediciones Uniandes.

Gordillo, Gastón. 2014. Rubble: The Afterlife of Destruction. Durham: Duke University Press.

Gracia, Jorge. 2003. "Distribución y dinámica espacial de la población en el litoral pacífico colombiano”. En Castillo y Alvis 2003, 250-261. 
Herrera, Marta. 2016. El conquistador conquistado. Awás, cuayquer y sindaguas en el Pacífico colombiano, siglos XVI-XVIII. Bogotá: Ediciones Uniandes.

Ideam. 2014. Pronóstico de pleamares y bajamares en la costa pacífica colombiana. Bogotá: Ministerio de Ambiente, Vivienda y Desarrollo Territorial.

Ingold, Tim. 2000. The Perception of the Environment. Londres: Routledge.

-. 2011. Being Alive: Essays on Movement, Knowledge and Description. Londres: Routledge.

—. 2013. “Los materiales contra la materialidad”. Papeles de Trabajo 7 (11): 19-39.

Leal, Claudia. 2000. “Manglares y economía extractiva”. En Geografía humana de Colombia. Los afrocolombianos, tomo VI, 318-344. Bogotá: Instituto Colombiano de Cultura Hispánica.

-. 2008. "Disputas por tagua y minas: recursos naturales y propiedad territorial en el Pacífico colombiano, 1870-1930". Revista Colombiana de Antropología 44 (2): 409-438. http:// www.icanh.gov.co/nuestra_entidad/grupos_investigacion/antropologia_social/publicaciones_seriadas_antropologia/5862.

Leal, Claudia y Eduardo Restrepo. 2003. Unos bosques sembrados de aserríos. Historia de la extracción maderera en el Pacífico colombiano. Medellín: Colciencias; ICANH; Universidad de Antioquia; Universidad Nacional de Colombia.

Leal, Claudia y Shawn van Ausdal. 2014. "Paisajes de libertad y desigualdad: historias ambientales de las costas pacífica y caribe de Colombia”. En Desigualdades socioambientales en América Latina, editado por Barbara Göbel, Manuel Góngora-Mera y Astrid Ulloa, 169-209. Bogotá; Berlín: Universidad Nacional de Colombia; Ibero-Amerikanisches Institut.

Leyva, Pablo. 2003. "Vulnerabilidad de la zona costera colombiana ante el cambio climático: aspectos generales del cambio climático. El efecto invernadero”. En Castillo y Alvis 2003, 138-154.

Losonczy, Anne Marie. 1993. "De lo vegetal a lo humano: un modelo cognitivo afrocolombiano del Pacífico”. En Revista Colombiana de Antropología 30: 38-57. http://www.icanh. gov.co/nuestra_entidad/grupos_investigacion/antropologia_social/publicaciones_seriadas_antropologia/8498.

-. (1997) 2006. La trama interétnica: ritual, sociedad y figuras de intercambio entre los grupos negros y emberá del Chocó. Bogotá: ICANH.

McNeill, John. 2005. “Naturaleza y cultura de la historia ambiental”. Nómadas 22: 12-25.

Mosquera, Gilma. 1993. "La vivienda rural en el Chocó”. En Colombia Pacífico, tomo 2, editado por Pablo Leyva, 496-517. Bogotá: Fondo para la Protección del Medio Ambiente José Celestino Mutis.

-. 2010. Vivienda y arquitectura tradicional en el Pacífico colombiano. Patrimonio cultural afrodescendiente. Cali: Universidad del Valle.

Motta, Nancy. 1998. "Madera contra cemento. Dinámicas culturales de los pueblos negros del Pacífico”. En Cuadernos del Pacífico 3: 43-56.

-. 2005. Gramática ritual. Territorio, poblamiento e identidad afropacífica. Cali: Universidad del Valle. 
Motta, Nancy y Aceneth Perafán. 2010. Historia ambiental del Valle del Cauca: geoespacialidad, cultura y género. Cali: Universidad del Valle.

Oslender, Ulrich. 2004. "Geografías de terror y desplazamiento forzado en el Pacífico colombiano: conceptualizando el problema y buscando respuestas”. En Conflicto e invisibilidad. Retos en los estudios de la gente negra en Colombia, editado por Eduardo Restrepo y Axel Rojas, 35-52. Popayán: Universidad del Cauca.

-. 2008. Comunidades negras y espacio en el Pacífico colombiano. Hacia un giro geográfico en el estudio de los movimientos sociales. Bogotá: Universidad Colegio Mayor de Cundinamarca; ICANH; Universidad del Cauca.

Palacio, Germán. 2002. "Notas sobre la noción de conflicto ambiental: ¿un nuevo matiz en el análisis histórico?”. En Repensando la naturaleza. Encuentros y desencuentros disciplinarios en torno a lo ambiental, editado por Germán Palacio y Astrid Ulloa, 193-203. Bogotá: Universidad Nacional de Colombia; Imani; ICANH.

Pedrosa, Álvaro. 1996. "Paisaje y cultura”. En Pacífico. ¿Desarrollo o diversidad? Estado, capital y movimientos sociales en el Pacífico colombiano, editado por Arturo Escobar y Álvaro Pedrosa, 29-40. Bogotá: Cerec.

Perafán, Aceneth. 2013. Valle del Cauca: un estudio en torno a su sociedad y medio ambiente. Cali: Universidad del Valle.

Restrepo, Eduardo. 1996a. "Economía y simbolismo en el 'Pacífico negro”. Tesis de pregrado, Departamento de Antropología, Universidad de Antioquia, Medellín.

-. 1996b. "Los tuqueros negros del Pacífico sur colombiano". En Renacientes del guandal: "grupos negros" de los ríos Satinga y Sanquianga, editado por Jorge Ignacio del Valle y Eduardo Restrepo, 243-348. Bogotá: Universidad Nacional de Colombia, sede Medellín; Biopacífico.

Robertson, Kim. 2003. "Geomorfología litoral y amenazas naturales en la costa pacífica colombiana”. En Castillo y Alvis 2003, 110-120.

Vanín, Alfredo. 1996. "Lenguaje y modernidad”. En Pacífico. ¿Desarrollo o diversidad? Estado, capital, y movimientos sociales en el Pacífico colombiano, editado por Arturo Escobar y Álvaro Pedrosa, 41-65. Bogotá: Cerec.

Vasco, Luis G. 2010. "Recoger los conceptos en la vida: una metodología de investigación solidaria”. Consultado el 8 de junio del 2018. http://www.luguiva.net/articulos/detalle. aspx?id=85.

West, Robert. (1957) 2000. Las tierras bajas del Pacífico colombiano. Bogotá: ICANH.

Worster, Donald. 2008. Transformaciones de la tierra. Montevideo: Coscoroba. 